\title{
Sport Products and Services in Sport Demand Model based on Heckman Model
}

\author{
Hongbo Zhang* \\ Heilongjiang University, Harbin, 150001, China
}

\begin{abstract}
On the basis of an in-depth analysis of the connotation and characteristics of sport demand, according to family Becker production function theory, through economic model analysis of the impact mechanism of age, income, leisure time, sport skills, wage rates and prices and other factors on the sport demand and consumption. Take Beijing city as an example. The collection of domestic sport demand and sport related consumption of the actual data, using Heckman two stage estimation of the econometric test on the theoretical expectations model, and then put forward the expansion of sport demand, increase the countermeasures and suggestions of sport consumption.
\end{abstract}

Keywords: sport demand; household production function; consumer utility; economic model; Heckman model

(Submitted on February 9, 2018; Revised on March 15, 2018; Accepted on April 15, 2018)

(C) 2018 Totem Publisher, Inc. All rights reserved.

\section{Introduction}

Since the reform and opening up, China's economic and social development has made remarkable achievements. People's living standard has improved. Leisure time has increased and various kinds of leisure need to expand. As one active leisure aspect, sport on the whole tends to rise up. However, compared with developed countries, bigger gaps exist for the level of participation in and consumption of sport in our urban and rural residents [3,8]. In 2014, the number of people who often do physical exercises throughout the country reaches $28.2 \%$, of which, urban and rural residents who exercise regularly at 16 years old and above take up only $8.3 \%$ of the overall national population at 16 years old and old. The average sport consumption is RMB593 annually, only $8.4 \%$ of per-capita total consumption expenditure.

During the period of the Twelfth Five-Year Plan for National Economic and Social Development of the People's Republic of China, Chinese sport development ushers in the new period of strategic opportunity. Expanding sport demands and improving sport participation rate and consuming level is the intrinsic requirement to promote the effective implementation of our national fitness program and important foundations to boom the sport market and promote the development of the sport industry in faster and better manner, which has practical significance to complete our goal for building a powerful country of sport. The effective implementation of national fitness program needs each sector to proactively increase the offerings of sport resources and products [5,6,7], but such offerings have to be done with a purpose. That is, it should really meet with actual demands of the masses; on the other hand, the development and expansion of sport industry depends on the cultivation and exploration of sport consumption market; the objective of production is to consume. Constant innovative and expansion of consumption needs are driving forces for sustainable and stable development of sport industry $[9,10]$.

The theory on physical demand is one of the most fundamental and core contents in sport economics; but very few theoretical studies are conducted in the paradigm of economic theory. In the paper, on the basis of in-depth investigation of sport demand connotation and features, and according to Family Production Function by Becker, by the economic model 
$[1,2]$, we analyze the effect law and action mechanism of factors like age, income, sport skill, spare time, wage and price on sport demand and consumption; further on that condition, we take Beijing for instance. We collect residents' actual data about sport demand and consumption. Then by means of two-step estimation model by Heckman, we do quantitative inspection of the aforesaid theoretical expectation [4].

\section{Concept and characteristics of sport demand}

\subsection{Concept discrimination}

The definition of general commodity demand in economics is: at a certain period of time, in an established price level, the number of goods to consumers is willing and able to purchase. Consumer's purchasing desire and purchasing power is the basic factors of effective demand. Sport activities and general merchandise are significantly different. According to the basic characteristics of sport activities, it can be divided into participatory sport and ornamental sport, no matter what type; in essence, the completion of sport activities needs to put into the relevant goods or services, but also need to consume personal time. People participate in sport activities, not only need to pay the price of the relevant goods / services, but also need to pay the opportunity cost of time. For some consumers, the time limit for sport needs may be far greater than the economic limit. According to the survey, in the crowd does not participate in physical exercise, because there is no time to participate in the highest proportion of the number of physical exercise, for 33.8\%. In the sport crowd, the main obstacle to their participation in physical exercise is "lack of time", accounting for $41.2 \%$. Therefore, the definition of sport needs must consider the time constraints. This study from the angle of economics "sport demand" is defined as: a certain period of time, the consumer to satisfy the spiritual and material (body), in a variety of market products / services price level and time cost, the number of sport consumption is willing.

\subsection{Two types of motivation: consumer utility and investment income}

Sport demand may be derived from two types of motivation. One is the pursuit of instant consumer utility. People who participate in sport activities can directly obtain physiological or psychological satisfaction. For example, skiers can obtain both physical and mental relaxation and pleasure, watching gymnastics and figure skating competitions can allow one to enjoy the beauty, and watching football can give an excited feeling. Consumer is a direct profit by Sport, which can be directly into the consumer utility function. In addition, most participating sports can give people a healthy body, and health itself can be considered as a kind of consumer utility. There is also the pursuit of investment returns in the future. Physical exercise can be formed in the human capital of the health capital; it can extend the working time and improve the quality of work, occupy the advantage in the labor market and earn more. Studies have shown that compared to not participating in sport activities of the workers, participants in sport activities increase workers labor productivity by an average of $0.6 \%$ to $10 \%$. Plus, the average annual leave less $17 \mathrm{~h}$, and health care costs $\$ 261$ less. Consumers is a future income by sport; people are willing to spend time to participate in the "exercise" and "fitness" like sport, because they expected future utility gain enough to make up for immediate participation in sport activities of money expenditure and take up the opportunity cost of time. Different people have different motivations for sport activities, which may be related to age, experience and other factors. Usually, young people are more likely to want to get immediate pleasure through sport activities, but with age, they often turn to the healthy sport activities.

\section{Sport demand model based on Family Production Function}

\subsection{Family Production Function}

General demand theory in microeconomics has great limitation in analyzing and explaining sport demand, because it assumes the effectiveness of consumers originates from goods that are directly bought from market and does not consider the influence of time factor on the demand. Instead, influential factors except price and income are often put in the black box to the fondness of consumers. Comparatively, Family Production Function proposed by Becker in 1965 is more applicable for economic analysis of sport demand. In his point of view, family is not the only consumer unit that seeks for utility maximization and also production unit. Integrate capital goods, raw materials and labor; it produces useful articles of consumption. Family chooses the best combination that can produce consumption goods as to realize the maximization of utility function. Either from watching the game, or joining in the exercise, it can be regarded as so-called family production activity. The general expression for the family production function is, it is shown in Equation (1).

$$
C_{i}=c_{i}\left(X_{i}, T_{i}\right)
$$


Where, $X_{i}$ and $T_{i}$ denote the input amount and time of commodity / services in the family in production, when using the venue, equipment and other capital goods, $X_{i}$ showed their provide service flow.

\subsection{Demand model for sport as consumption goods}

Suppose the main motivation of consumers joining in sport is seeking for immediate consumption utility; that is, receiving from sport the physiological or psychological satisfaction such as relaxation, excitement, stimulus, comfort, aesthetics. Hence, sports can import to the utility function of consumers.

\subsubsection{Basic framework}

Consumption activities that can gain the utility are classified into two kinds. $\mathrm{S}$ means sport activity. C means other consumption activities. $U$ is level of utility of consumers. The basic framework of sport demand model is as follows, it is shown in Equation (2) - (6).

$$
\begin{gathered}
U=u(S, C) \\
S=s\left(X_{s}, T_{s}\right) \\
C=c\left(X_{c}, T_{c}\right) \\
P_{s} X_{s}+P_{c} X_{c}=R=V+w T_{w} \\
T=T_{w}+T_{s}+T_{c}
\end{gathered}
$$

Equation (2) is consumer utility function, implying that utility all comes from consumption activities $\mathrm{S}$ and $\mathrm{C}$. Equation (3) and (4) are respectively family production function of sport and other consumption activities. Equation (5) is budget constraint condition, meaning that consumer's gross expenditure for buying diversified commodities/services shall be equal to disposable personal income. Equation (6) is time limit condition, i.e. the time in working and the time in sport and other consumption activities, which shall amount to the available total time, indicating that consumer's time resource is likewise limited. In order to simplify the analysis, the production technology of Leontiff constant coefficient is assumed in the family production function. It is shown in Equation (7).

$$
\begin{aligned}
& X_{s}=x_{s} S \\
& X_{c}=x_{c} C \\
& T_{s}=t_{s} S \\
& T_{c}=t_{c} C
\end{aligned}
$$

$x_{s}$ and $t_{s}$, respectively, said the production of 1 units of sport activities required to invest in sport goods / services and spend time. The significance of $x_{c}$ and $t_{c}$ represents the corresponding. The family production function takes into the time and budget constraints, can be a total revenue budget constraint. It is shown in Equation (8)

$$
\left(P_{s} x_{s}+w t_{s}\right) S+\left(P_{c} x_{c}+w t_{c}\right) C=V+w T
$$

\subsubsection{Equilibrium condition}

The objective of the consumer is to achieve the maximization of personal utility level through the best alternative quantitative combination of sport and other consumption activities in the case of double restraints of income and time. Thus, the solving of equilibrium condition is deemed to solve the utility function in the total restraint condition. It is shown in Equation (9). 


$$
\frac{U_{c}^{\prime}}{U_{c}^{\prime}}=\frac{\pi_{s}}{\pi_{c}}
$$

The meaning of the equilibrium condition is that consumers choose $\mathrm{S}$ and $\mathrm{C}$ to meet the ratio of the two kinds of activities of the marginal utility ratio is equal to the relative price of the ratio of this condition. It is shown in Figure 1 . The relative price of goods / services includes not only the price of money, but also the opportunity cost of time, which will also affect the consumer demand and the corresponding resource allocation decision.

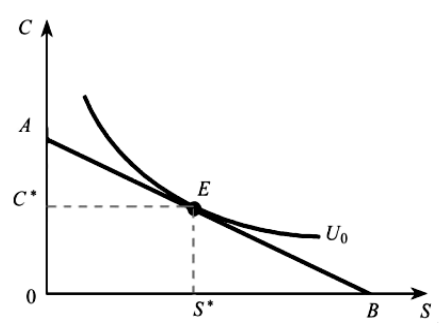

Figure 1. Equilibrium of sport demand model for consumer utility

Consumer's demand for sport commodity/service comes from and is subject to sport demand. Previously, we assumed family production activity takes the technical form of Leontiff fixed coefficient; so, consumer's optimal consuming volume for sport product/service will be in direct proportion to sport demand. It is shown in Figure 2.

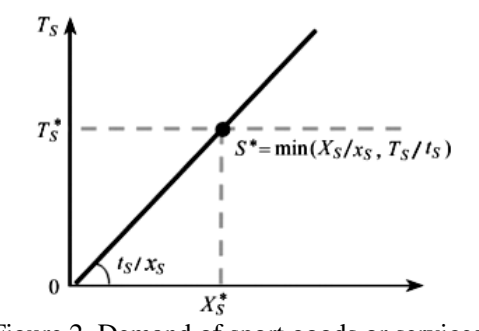

Figure 2. Demand of sport goods or services

\subsubsection{Influential factors}

Based on equilibrium condition, we can further analyze the impacts of changing factors on sport demand and consumption, like sport goods/service price, time investment in single sport activity, wage rate and non-wage income.

Inference 1: When sport is normal goods, consumer's sport demand will increase with increasing non-wage income. The increase in non-wage income will make the budget line intercept increases. The budget line moves outward. It is shown in Figure 3. Because the sport activities belong to the normal goods usually sense of luxury (even the income elasticity of demand, 0), non-wage income and consumer demand for sport will increase.

Inference 2: If the cost of sport goods/service descends, or the time invested in single sport activity reduces, consumer's sport demand and the consumption volume of sport goods/service will ascend. Sport service and commodity prices, or the unit sport needs time to reduce input (such as exercise efficiency, reduce transportation time etc.), relative prices will make physical activity $\left(\pi_{s} / \pi_{c}\right)$ reduced the budget line outward rotation. It is shown in Figure 4.

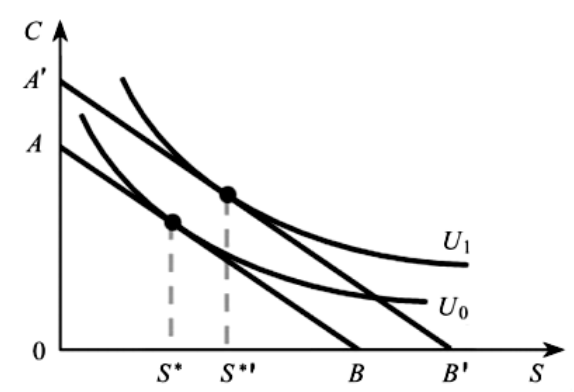

Figure 3. How the shift of unearned income affects general equilibrium 


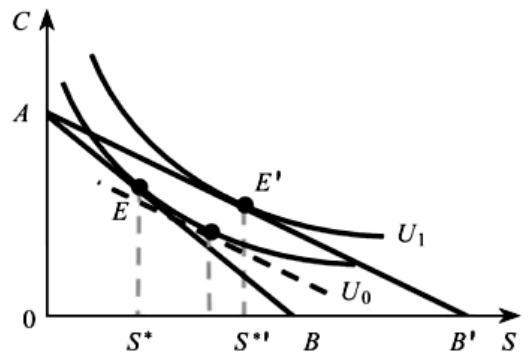

Figure 4. How the shift of market price affects general equilibrium

Inference 3: The influence of raised wage rate on consumer's sport demand is dependent on the time investment percentage of the two activities $\mathrm{S}$ and $\mathrm{C}$. The relative price ratio of wage rate increase will also change the total income of consumers and two kinds of consumption activities. Thus, the two aspects of income effect and substitution effect are influenced.

\subsection{Demand model of sport as investment goods}

Suppose the main motive of consumer participating sport activities is to become stronger and healthier, which leads to increase working time and quality as to acquire higher labor market income. Then, sport activity becomes a way of health capital investment, bringing future benefits to consumer.

\subsubsection{Basic framework}

According to health capital theory by Grossman, health capital is developed similarly as fixed asset and the withdrawal as depreciation cost. A person can choose to do health capital investment at each stage in the premise of maximized total utility. The utility function of consumer life is as follows. It is shown in Equation (10).

$$
U=u\left(C_{0}, C_{1}, C_{2}, \ldots, C_{i}, \ldots C_{n}\right)
$$

$C_{i}$ represents a combination of consumer activities in the period n, I represents the number of lives. Assume that physical education is the only way to improve health, the way consumers produce (investment) health and other consumer goods are expressed as a function of family production. It is shown in Equation (11) and (12).

$$
\begin{gathered}
C_{i}=c_{i}\left(X_{i}^{c}, T_{i}^{c}, E_{i}^{c}\right) \\
h_{i}=S_{i}=s_{i}\left(X_{i}^{s}, T_{i}^{s}, E_{i}^{s}\right)
\end{gathered}
$$

Consumers in making investment decisions are faced with two aspects of income and time constraints. It is shown in Equation (13) and (14).

$$
\begin{gathered}
\sum \frac{P_{i}^{s} X_{i}^{s}+P_{i}^{c} X_{i}^{c}}{(1+r)^{i}}=\sum \frac{w_{i} T_{i}^{w}}{(1+r)^{i}}+v \\
T_{i}^{w}+T_{i}^{s}+T=T_{i}^{h}
\end{gathered}
$$

Total health time $\left(T_{i}^{h}\right)$ of the consumer is determined by the stock of health capital. It is shown in Equation (15).

$$
T_{i}^{h}=\varnothing_{i} H_{i}
$$

$H_{i}$ is the consumer's health capital stock level I period, $\varnothing_{i}$ is healthy days for each unit of health capital. Grossman's health capital theory believes that the health of the time is consistent with the law of diminishing marginal returns. It is shown in Figure 5. 


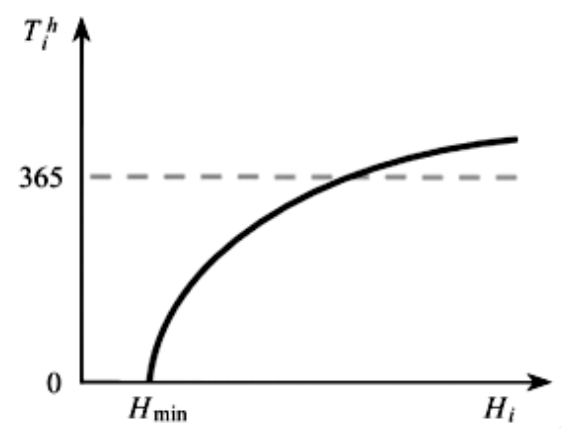

Figure 5. Production of health time

\subsubsection{Equilibrium condition}

When time and income are both constrained but with certain family production technologies, consumers aim to choose the best health capital stock $H_{i}$ at the $i t h$ stage to combine with consumption activity $C_{i}$ as to realize the maximization of the lifetime utility level. Since consumer's original health capital stock $H_{0}$ and depreciation rate $\delta_{i}$ of health capital are exogenously affected, from equation (10) and (14), we know consumer's optimal health capital stock is determined by the chose physical exercise volume $S_{i}$.

The equilibrium condition of the model is similar to that of the investment in fixed assets, and the consumption of the investment is equal to the marginal cost principle. In order to simplify the analysis, it is assumed that the marginal cost of physical exercise is constant. It is shown in Equation (16).

$$
w_{i} \frac{\partial T_{i}^{h}}{\partial H_{i}}=\frac{\partial G_{i-1}}{\partial S_{i-1}}\left(r+\delta_{i}\right)
$$

Diminishing marginal output $\left(\partial T_{i}^{h} / \partial H_{i}\right)$ of health capital, MEI curve to the right under the tilt, as shown in Figure 6.

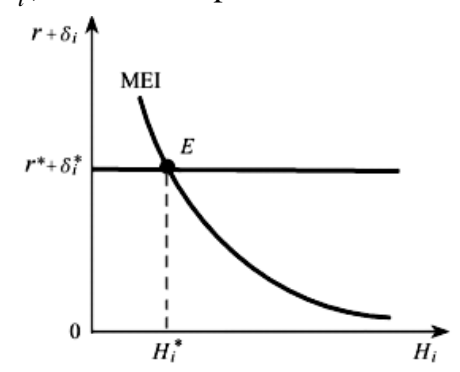

Figure 6. Equilibrium of sport demand model for investment benefit

If commodity/service and time invested in physical exercise can replace each other, then according to the theory on variable proportion, in order to make family production cost minimum, consumer will choose the most suitable way of physical exercise by following that the ratio of marginal input and output of the above two factors amounts to that of marginal cost. It is shown in Equation (17).

$$
w_{i} \frac{\partial S_{i} / \partial X_{i}^{s}}{\partial S_{i} / \partial T_{i}^{s}}=\frac{P_{i}^{s}}{w_{i}}
$$

\subsubsection{Influencing factors}

Using the above equilibrium relationship, we can further analyze the influence of these factors on sport demand like consumer's age, wage rate, sport goods/service price, and sport skills. 
Deduction 1: With the growing of age, the rate of personal health capital depreciation becomes higher. Consumer's health capital stock will reduce but sport demand will increase. Health capital depreciation rate $\left(\delta_{i}\right)$ and age related, health loss in the elderly. Consumption will be faster than young people. After reaching a certain age, as the age continues to increase, the depreciation rate will increase, which will make the level of the health capital supply curve upward movement. It is shown in Figure 7.

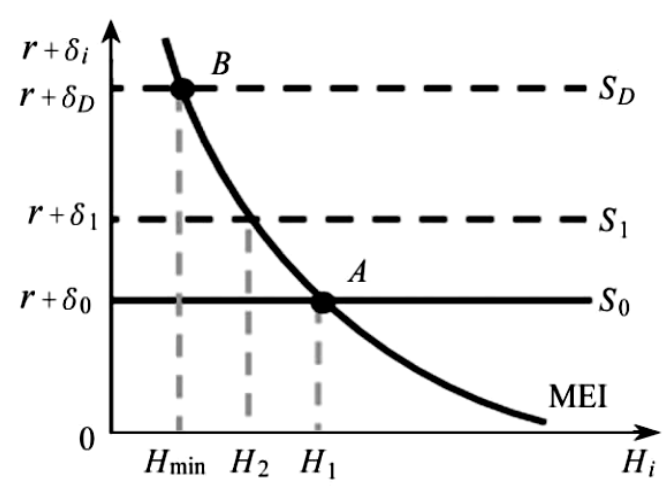

Figure 7. How the shift of age rate affects general equilibrium

Deduction 2: After wage rate grows, the selected health capital stock and demand for physical practices will go up alongside. If two elements invested in the sport activity are alternative, consumer will target on the production-intensive way of exercising, i.e. higher benefit in unit time. Wage rate $(w)$ changes will affect the marginal return on health capital. It will affect the marginal cost of physical exercise $\left(w_{i} \partial T_{i}^{h}\right)$. The higher the wage rate of consumers, the higher the marginal rate of return on health capital. On the other hand, the higher the income, the more valuable the consumer's time, the cost of physical exercise will be higher. Since time cost is only part of the total cost of health production, the rate of increase in the cost of the wage rate is less than the magnitude of the revenue growth. As a result, the net result of the above changes will increase the marginal efficiency of investment, the MEI curve shifts to the right, and the increase of the healthy capital stock of consumer choice. It is shown in Figure 8.

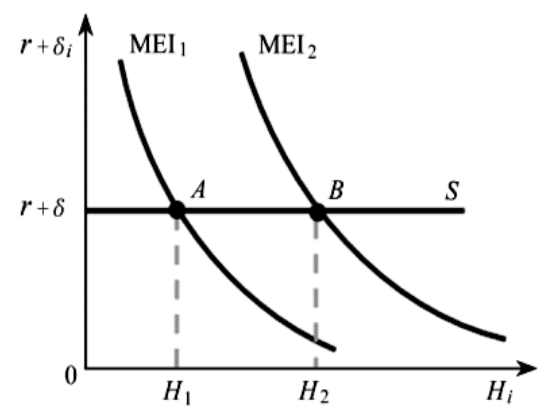

Figure 8 . How the shift of wage rate affects general equilibrium

Deduction 3: After the cost of sport goods/service runs high, consumer's health capital stock and sport demand will debate accordingly.

Sport products / services price changes will only affect the marginal cost of physical exercise, and will not affect the return of healthy capital. Increase in sport product / service price will make the mobile MEI curve to the left. Consumers choose to hold the stock of health capital reduction; sport demand and sport product / service consumption will be reduced accordingly.

Deduction 4: After consumer's sport skills are improved, its health capital stock and sport demand stay higher but fewer demand for elementary investment.

Because the marginal revenue is unchanged, the marginal efficiency of capital investment in health (MEI), Mobile MEI curves to the right. Consumers will increase their holdings of health capital, and the demand for physical exercise will increase. Due to the assumption that the marginal productivity of capital health decline, MEI curve of elasticity is less than 1 , so the sport demand growth rate is less than the rate of increase of motor skills. Consumers of investment demand will reduce. Here, we consider the influence of sport skills in exercising efficiency. As a matter of fact, from the part of demand, 
persons with higher sport skill often know better about health benefit brought by physical exercise, love more doing exercises and pursue well-built body. In other words, when other conditions are same, they may have higher interests in health and physical exercises so their demands for sport would be higher.

\section{Empirical validation of sport demand model}

\subsection{Econometric models and estimation methods}

In order to test the theoretical expectation, the measurement model was established. It is shown in Equation (18).

$$
S_{i}=\beta A_{i}^{s}+\varepsilon_{i}^{s}
$$

To deal with the selection decision problem, we utilize Heckman's two-step estimation model to conduct quantitative analysis. First, construct probit model of all samples; estimate by maximum likelihood method to get parameters of each influential elements and calculate inverse Mills ratio according to parameter $\beta$ and error term $\varepsilon_{i}^{s}$. Secondly, substitute inverse Mills ratio into the metric model for sport consumption expenditure and sport time investment; estimate with least square method (OLS). Heckman's two-step estimation method requires that explanatory variable $\left(A_{i}^{s}\right)$ in the first step shall contain some variables which have impacts on sport participation decision but are missing in the second step. So, in the sport decision estimation model, apart from income, age, level of education, social economic variables like gender, marriage and employment status are included.

\section{2. data sources}

Take Beijing for instance, and give out 300 questionnaires to respondents of different position, age and gender. We take back 273 copies; response rate reaches 91\%; of them, 248 copies can accurately reflect survey information, effective response rate reaching $82.7 \%$. Respondents are consisted of two groups: regular participation in sport activity and nonparticipation. The questionnaire covers questions like motive of sport participation, sport consumer expending, exercising time, social demography variables (age, gender, marriage, level of education) and economic variable (income and employment status). Further on, physical exercising time is gross time by hour each week for doing exercises including travelling time; employment status includes in-service and others; level of education refers to three levels: below high school, high school, graduation and above.

\subsection{Estimation results and discussion}

In the first step estimation, we use maximum likelihood (ML) method to validate selection model. Dependent variable is discrete variable, regular participation $=1$, and non-participation $=0$. Independent variable includes age, gender, levels of education, marriage, incomes and employment status, used to explain consumer's sport participation decision. Table 1 gives result of parameter estimation. Since dependent variable is discrete variable, estimated value of parameters can't reflect directly the size of contribution. So Table 1 shows marginal effective value of independent variable, meaning that when explanatory variable changes one unit, the probability of dependent variable equal to 1 (regular participation) is too small. Results reveal that explanatory variable is statistically significant and basically consistent with theoretical expectation.

First of all, consumer age is negatively correlated with sport demand; with the increase in age yearly, the possibility of individual taking part in physical sport decreases by $0.5 \%$. The influence of age on sport demand is too complicated. Theoretical sport demand may be altered from four aspects. Physiologically, age increase is associated with health level and physiological function; based on the above analysis of investment demand model, when individual enters to certain life stage, sport demand rises along with increasing health depreciation rate; Psychologically, age growth means varying motivation of and attitude to sport demand, physical needs based on consumption utility of amusement and entertainment may decrease with growing age. Socially, society is more tolerant to the elder in terms of non-participation and body shape; Economically: individual's usable time and capital are both related with age; however, in the whole lifetime cycle of human, there is no linear variation relationship between them. In the model, influences by income and employment status are suppressed, measuring results reflect impacts by consumer's motivation of sport participation and physical condition change, the negative effects caused by weakened recreational consumption motive take dominance. 
Table 1. Estimating results of the First-stage Heckman model

\begin{tabular}{|l|l|l|}
\multicolumn{2}{l}{ Table 1. Estimating results of the First-stage Heckman model } \\
\hline Age & Marginal effect & $\mathrm{P}$ \\
\hline Income & -0.05 & 0.66 \\
\hline high school & 0.02 & 0.10 \\
\hline Bachelor degree or above & .063 & 0.27 \\
\hline Female sex & 0.10 & 0.00 \\
\hline Married & -0.33 & 0.08 \\
\hline Job & -0.15 & 0.00 \\
\hline$P-R^{2}$ & -0.12 & 0.33 \\
\hline
\end{tabular}

Secondly, higher income means higher probability for participation in sport activities; however, its influential scale is rather small. When income increases by 10,000 per time, the possibility for individual joining sport activity increases by $0.2 \%$. During the survey, it's hard to judge high income originates from wage earnings or wealth. According to theoretical model prediction, two parts constituting income has different effects on sport demand. Consumers who seek for return from health investment will choose to do more exercises due to the higher wage rate, extending health days and gaining more labor rewards. Comparatively, consumers who seek for recreational consumption utility would reduce physical demand due to rising time opportunity cost as a result of ascending wage rate. The increment of wealthy income will boost sport demand for consumption as purpose. Measuring experiment demonstrates the result of interaction of those influential factors and consumer's income is positively correlated with sport needs.

Thirdly, with a higher level of education, consumers are more likely to regularly participate in sport activities. The 2014 Status Survey Bulletin about Chinese Urban and Rural Residents' Participation in Physical Exercises reports that among the population doing physical exercises, 30.7\% have gained sport skills at school, which is consistent with many researchers' viewpoint. That is to say, individual's motor techniques are mostly acquired from school physical education. So longer inschool time may mean higher sport skills. Metric results display dummy variables that represent the level of education conform to the prediction of investment demand model. The higher the level of education is, the higher the demand for sport is.

In addition to a few influential factors discussed in the theoretical part, three control variables are introduced to measuring model in the paper: gender, marriage and employment status. It unveils that the married group keeps being less possible to do regular exercises than the unmarried by $1.5 \%$; in-service population is less regular to participate in sport than control group (including unemployment, laid-off, retired, household person, students) by $1.2 \%$. Negative marginal effects that occur may be the time opportunity cost of in-service person is higher but less flexible working hours. After the differences in employment and income are controlled, female is less likely to do regular physical exercises than male by $3.3 \%$, probably owing to their family responsibility, interest and hobbies. In the second step estimation, the paper employs the least square method (OLS) to verify time investment model and consumption expenditure model. Calculate inverse Mills ratio according to the first-step regression result and introduce it to the second-step estimation model. Correlation exists between error terms between participation decision model and time investment/consumption expensive model. By using the 2-step estimation, selective bias to the estimated value of other parameters is avoided. Estimated results show that most variables are statistically significant and display opposite parameter symbols in two equations. It is shown in Table 2 .

Table 2. Estimating results of the second-stage Heckman model

\begin{tabular}{|l|l|l|l|l|}
\hline \multirow{2}{*}{} & \multicolumn{2}{l|}{ Table investment model } & \multicolumn{2}{l|}{ Consumption expenditure model } \\
\cline { 2 - 5 } & Parameter estimation & $\mathrm{p}$ & \multicolumn{2}{l|}{ Parameter estimation } \\
\hline Age & 0.772 & 0.50 & -13 & 0.34 \\
\hline Income & -0.31 & 0.00 & 0.915 & 0.12 \\
\hline high school & -37 & 0.08 & 102 & 0.59 \\
\hline Bachelor degree or above & -67 & 0.44 & 77 & 0.11 \\
\hline Constant & 330 & 0.00 & 629 & 0.00 \\
\hline Adj $R^{2}$ & 0.62 & & 0.558 & \\
\hline D-W stat & 0.53 & & 0.871 & \\
\hline
\end{tabular}

\section{Conclusions}

To improving the participation rate of sport in these groups, it is faster to realize the goal of improving the overall level of participation of the whole people. Give full play to the positive role of school physical education in improving sport skills, and training of sport awareness and interest. To expand the policy implementation of sports, price subsidies of venues and facilities cannot be solely relied on. The supply of sport should fully consider the resource constraints faced by different income groups, and meet the needs of different levels of the government and the market. To meet the basic needs of sport of low-income groups, the micro level can extend sport service coupons and other measures. At the macro level, needs can be met through policy funds to low-income areas and other measures. 


\section{References}

1. C. Breuer, K. Hallmank, "Socio-economic Partterns of Sport Demand and Ageing”, Eur rev act, pp.61-70,2011

2. F. Conalter, "Sport Participaton:Price or Priorities", Leisure Stud, pp.171-182,1993

3. H. Y. Gao, "Western Economics", Beijing: People's University Press, pp.587-590,2011

4. M. Grossman, "The Concept of Health Capital and The Demand for Health", J political Economy, pp.223-255,2014

5. B. Q. Luo, Yaodong, An, "Probe into Influence of Sport on Enhance the Level of Human Resources", Journal of Capital Institute of Physical Education, vol.14, no.3, pp.20-22,2012

6. W. Li, "Association Model, Influencing Factors and Evaluation of Chinese Athletes' Competition Failure", Beijing Sport University, 2014.

7. B. Marshall, "Economic Theory. Liu Shenglong, Translation", China Social Science Press, pp.120-122,2007

8. Y. Peng, "Based on Grey Markov Theory of Physical Training Effect Prediction and Evaluation Model", Military Operations Research and Systems Engineering, vol.3, pp.59-61,2013

9. Q. Sun, Y. Gao, "Economic Thinking on The Development of The Sport Industry in China", Journal of Nanjing Sport Institute (SOCIAL SCIENCE EDITION), vol.20, no.5, pp.33-35,2016

10. H. M. Xi, N. J. Wei, Z. Peng, "China City Consumers' Individual Differences on Sport Consumption Effect of Concept and Consumption Behavior", Sport Science, vol.30, no.3, pp.30-35,2010

Hongbo Zhang received his B.S degree from Shenyang Sport University and received his M.S degree from Heilongiiang University. He is a lecturer at Heilongjiang University. He is in the research of Physical Education. 